\title{
The design of a study aid for synthesizing instruction
}

\author{
Patricia Youngblood, PhD \\ University of New England, Northern River
}

\begin{abstract}
Experts in the field have acknowledged that the 1990s bring new challenges to the field of educational technology. The traditional models for designing instruction will need to be modified to address the new capabilities of emerging technologies (Alien, Dodge \& Saba, 1989; Hannafin \& Rieber, 1989). And research must be conducted to guide the development of instructional design and technology theory and models (Klein, 1989; Reigeluth, 1989).

In his review of the status of current research in instructional technology (IT), Clark (1989) recommends that future research must go beyond descriptive research methods to adopt prescriptive research methodology. He recommends that IT researchers use the more basic, descriptive research findings from individual differences and developmental psychology to create 'design prescriptions'. These prescriptions can then be used in design research to produce generalizations about the best methods to be used with specific tasks and learners to increase achievement and motivation. The study reported here is an example of this type of design research.
\end{abstract}

In this study the researcher used a prescriptive instructional design theory, the elaboration theory (Reigeluth \& Stein, 1983), to construct a study aid called a theoretical synthesizer and test its effectiveness in helping biology students learn genetics principles.

\section{The instructional problem}

A pervasive problem in science education at the college level is that too much emphasis has been placed on knowledge of isolated facts and concepts to the neglect of learning how to apply that knowledge to real world problems. This situation is compounded by pressures to incorporate new material in college level science courses to keep up with the rapid pace of scientific discoveries. College faculty are trying to teach an everexpanding curriculum within time constraints of a limited number of classes per semester or quarter term. Associated with this pressure to 
"cover the content" is a tendency for faculty to introduce new material at each class lecture, and to reduce the amount of class time spent on review and synthesis of the topics that were introduced previously As a result students must discover for themselves how the separate topics of the course are related by studying their class notes, textbooks, or other instructional resources.

If knowledge of relationships among ideas is an important educational goal, and time constraints limit the amount of direct instruction on this type of knowledge, then it would be beneficial to provide students with some type of instructional support to focus their independent study efforts toward learning relationships between and among the separate ideas that were presented in class. A synthesizer is one type of study aid which has been designed to help students gain this type of knowledge (Reigeluth \& Stein, 1983; Reigeluth, 1987). In the elaboration theory of instruction Reigeluth and Stein state that a synthesizer serves both a summarizing and a synthesizing function in helping students learn course content. Each synthesizer should consist of three parts: a generality, worked examples and practice items. In addition, they maintain that three types of synthesizers should be used to learn content in the cognitive domain: conceptual synthesizers, procedural synthesizers and theoretical synthesizers.

\section{Purpose and research questions}

The purpose of this study was to compare the effects of a set of study strategies called a theoretical synthesizer to an alternative study strategy, completing practice problems, and to a placebo treatment, studying genetics experiments. The effects of these study strategies on three learning outcomes were examined: knowledge of the separate genetics principles, knowledge of the interrelationships among the genetics principles and application of genetics principles to real world problems. In addition, the investigator studied the influence of students' prior achievement in biology on the learning outcomes, as well as students' satisfaction with the materials they used.

Four major research questions were addressed:

1. Do students who study and complete a theoretical synthesizer perform better on tests of a) knowledge of genetics principles, b) knowledge of interrelationships among principles and c) application of genetics principles than students who complete practice problems and students who study genetics experiments? (Synthesizer $>$ Practice Problems = Placebo)

2. Do students who complete practice problems perform better on tests of a) knowledge of genetics principles, b) knowledge of interrelationships 
among principles and c) application of genetics principles than students who study genetics experiments? (Practice Problems > Placebo)

3. Will students with lower prior achievement in biology benefit more from studying and completing a theoretical synthesizer than students with higher prior achievement? (An interaction effect)

4. Will students who study and complete a theoretical synthesizer express greater satisfaction with that study strategy than students who complete practice problems and students who study genetics experiments? (Attitudinal data)

\section{Theoretical framework}

Charles Reigeluth has proposed a prescriptive theory of instruction, called the elaboration theory (Reigeluth and Stein, 1983; Reigeluth, 1979; Reigeluth, 1987). One component of the elaboration theory of instruction is the periodic use of a synthesizing/summarizing strategy called a synthesizer, which is intended to teach the interrelationships among previously learned ideas. Van Fatten, Chao, \& Reigeluth (1986) explain that synthesizing is a macro-instructional strategy which is concerned with the organization of memory rather than with memory acquisition. In addition, they suggest that "the effects of a macro strategy should endure over longer periods of time and should more strongly influence transfer and problem solving than those of a micro strategy" (Van Fatten, Chao and Reigeluth, 1986). Therefore, the researcher hypothesized that learning the interrelationships among ideas (the content structure) would affect the organization of memory, and thus facilitate application of those ideas to problem situations in real life.

In addition, a synthesizer stimulates the recall of the previously learned, individual ideas that were presented in the previous instruction. This review function is a by-product which cannot be separated from the primary function of a synthesizer, which is to teach the interrelationships between and among the individual ideas that were previously taught. Therefore, the researcher further hypothesized that a synthesizer would help students recall the individual ideas that were presented in the initial instruction. In summary, the researcher hypothesized that students must learn the individual ideas of the content as well as how those ideas are interrelated in order to use the knowledge to solve problems.

Previous studies have investigated the effects of conceptual and procedural synthesizers on knowledge and application level learning (McLean, Yeh, \& Reigeluth, 1983; Chao \& Reigeluth, 1986). Results of these studies indicate that a visual format is more effective than a verbal format for learning relationships among concepts in one lesson, and that complete synthesizers for a set of lessons are more effective than partial ones for remember level learning. 
However, the most effective format and structure for synthesizers of theoretical content has not been determined. In fact, no empirical investigation of theoretical synthesizers has been conducted. Therefore, the purpose of this study was to determine whether a complete synthesizer for several lessons of theoretical content would be more effective than an alternative study strategy (completing practice problems) and a placebo treatment (studying text).

\section{Methods}

Design and procedure:

This study employed a three group, posttest only, randomized control group design to test the research questions. Subjects in each sample were randomly assigned to one of two treatment groups or to a placebo control group. All students received the same initial instruction in genetics by attending class lectures and laboratory sessions, and completing the related reading assignments. At the end of the initial instruction in genetics, students attended an in-class study session. At the study session the students were given 25 minutes to study either a synthesizer, a set of practice problems, or a narrative on the classic experiments in genetics (the placebo). After 25 minutes, all study materials were collected, and the students were given the posttest. Students were given 30 minutes to complete a 30 item test and a six item attitude questionnaire.

Sample:

Two samples of subjects were recruited for the study -- one sample from each section of an introductory college biology course. In the first section, 127 of the 160 enrolled students participated in the study. In the second section, 80 of 90 students enrolled in the course participated. The subjects in each sample were predominantly freshmen (51\% and 64\%) and sophomores (39\% and $21 \%)$.

\section{Instrumentation:}

The covariate in the study was prior achievement in biology, as measured by student performance on the first unit test given in each of the two sections of the biology course. The three dependent variables in the study were measured by student performance on three 10 item subtests of a test developed according to the researcher's test blueprint by two experienced biology teachers. The test was designed to measure three outcomes: 1) students' understanding of the individual genetics principles that were taught in the initial instruction, 2) students' understanding of the interrelationships between and among the genetics principles that were taught, and 3) students' ability to apply the genetics principles to real world problems. Reliability estimates for each of the subtests and for the total test were $.41, .53, .42$, and .68 for the first sample, and $.62, .64, .54$, and .82 for the second sample. Content validity of the outcome measures was 
established by having two content experts check the test items for consistency with unit behavioural objectives and with the test blueprint, as well as for accuracy and clarity. In addition, a six item attitudinal questionnaire was developed to assess subjects' satisfaction with the study materials they were given.

Data Analysis:

A multivariate analysis of covariance, with prior achievement in biology as the covariate, was performed on each of the two samples. In addition, the test of homogeneity of regression slopes was performed to determine whether there was a significant interaction effect between the covariate and the independent variable (type of study strategy used). Next, two orthogonal, a priori comparisons were performed to test the first two research questions. And finally, the Kruskal-Wallace analysis of variance for nonparametric data and the Chi Square statistic were used to analyze the attitudinal data.

\section{Results and conclusions}

Significant results were found despite the relatively low reliability estimates of the instruments used to measure the effects. Results of the analyses on the two samples showed that students in both samples who studied a theoretical synthesizer generally outperformed students who studied the alternative treatment as well as students who studied the placebo treatment. And students who studied the alternative treatment performed no better or worse than those who studied the placebo. It is likely that after a correction for attenuation, the actual effects of the experimental treatment would be larger (Guilford, 1954).

\section{Effects of the theoretical synthesizer}

In the first sample, students who studied a theoretical synthesizer performed significantly better than students who studied either practice problems or students who studied a narrative on genetics experiments for knowledge of genetics principles $(p<.01)$, and for knowledge of interrelationships among genetics principles $(p<.01)$. These students did not score significantly better for application of genetics principles $(p=.13)$. In the second sample, students who studied a theoretical synthesizer performed significantly better than the other two treatment groups for all three dependent measures: knowledge of genetics principles $(p<.01)$, knowledge of interrelationships among genetics principles $(\mathrm{p}<.01)$, and application of genetics principles $(\mathrm{p}<.01)$.

\section{Effects of the alternative treatment}

In the first sample, students who studied practice problems performed significantly better than students in the placebo group, who studied a narrative on genetics experiments, for only one of the dependent 
measures: knowledge of interrelationships among genetics principles $(p<.05)$. In the second sample, there were no significant differences between these two groups for any of the dependent measures.

\section{Interaction effect}

No interaction effect was found between the independent variable (type of study strategy used) and the covariate (prior achievement in biology) for either sample.

\section{Attitudinal data}

For both samples, nonparametric analyses of the attitudinal data showed that for every item addressing satisfaction with the study strategy used, students who studied the theoretical synthesizer gave it more favourable ratings than students who studied the practice problems or students who studied the narrative on genetics experiments.

\section{Educational importance of the study}

The results of this research provide further support for the use of synthesizers as one component of the elaboration theory of instruction. Previous studies investigated the effects of conceptual and procedural synthesizers. However, no research had been conducted on theoretical synthesizers prior to this study. Therefore, this study provides future researchers with one example of a theoretical synthesizer for genetics instruction that was designed according to the guidelines provided in the elaboration theory of instruction.

In addition, this study provides empirical support for the development of a theory of academic studying. In their synthesis of the research on academic studying, Anderson and Armbruster (1984) propose that both state and process variables contribute to students' success with studying. In this study, the subjects had no explicit knowledge of the criterion task, however, the practice items provided in both the synthesizer and the alternate treatment groups were consistent with the criterion task. Differences in knowledge of the content in the to-be-learned material and motivation were controlled by randomly assigning subjects to the three treatment groups. Thus, the focus of this study was on the text variables inherent in the recommended design of a synthesizer. The synthesizer provided an organizational structure that was intended to help students learn interrelationships. In addition, the synthesizer provided students with an opportunity to receive practice and feedback on examples that were similar to the criterion task. The alternative treatment provided only sample problems which were consistent with the criterion task. And the placebo treatment was not related to the criterion task. The findings suggest that the text variables of both organization of the material (provided in the generality or summary of genetics principles) and the 
structure of the synthesizer (the three parts-generality, worked examples and practice items) had significant effects on student learning.

And finally, this research may have implications for the design of both commercially produced and teacher-constructed study guides. These findings suggest that providing students with a set of study strategies, such as a synthesizer, for each unit of instruction in a course may be an efficient and effective way to help students review important principles and learn the interrelationships among the previous topics that were studied.

\section{References}

Allen, B. S., Dodge, B. J. \& Saba, E. (1989). An educational technology curriculum for converging technologies. Educational Technology Research and Development, 37(4), 47-54.

Anderson, T. H. \& Armbruster, B. B. (1984). Studying. In P. D. Pearson (Ed.), Handbook of reading research, 657-679. New York: Longman.

Chao, C. \& Reigeluth, C. M. (1986). The effects of format and structure of a synthesizer on procedural-decision learning. IDD\&E Working Paper No. 22. Syracuse University, Syracuse, NY.

Clark, R. E. (1989). Current progress and future directions for research in instructional technology. Educational Technology Research and Development, 37(1), 57-66.

Guilford, J. P. (1954). Psychometric methods. New York: McGraw-Hill.

Hannafin, M. J. \& Rieber, L. P. (1989). Psychological foundations of instructional design for emerging computer-based instructional technologies, Part II. Educational Technology Research and Development, 37(2), 102-114.

Klein, J. D. (1989). Enhancing instructional design and technology academic programs: A summary of the fifth meeting of the professors of instructional design and technology. Educational Technology Research and Development, 37(3), 103-106.

McLean, L., Yeh, N. K., \& Reigeluth, C. M. (1983). The effects of format of synthesizer on conceptual learning. IDD\&E Working Paper No. 13. Syracuse University, Syracuse, NY.

Reigeluth, C. M. (1979). In search of a better way to organize instruction: The elaboration theory. Journal of Instructional Development, 2, 8-15.

Reigeluth, C. M. (1987). Lesson blueprints based on the elaboration theory of instruction. In C. M. Reigeluth (Ed.), Instructional theories in action: Lessons illustrating selected theories and models, 245-288. Hillsdale, NJ: Lawrence Erlbaum Associates.

Reigeluth, C. M. (1989). Educational technology at the crossroads: New mindsets and new directions. Educational Technology Research and Development, 37(1), 67-80. 
Reigeluth, C. M. \& Stein, E. S. (1983). The elaboration theory of instruction. In C. M. Reigeluth (Ed.), Instructional design theories and models: An overview of their current status, 335-381. Hillsdale, NJ: Lawrence Erlbaum Associates.

Sari, I. E \& Reigeluth, C. M. (1982). Writing and evaluating textbooks: Contributions from instructional theory. In D. H. Jonassen (Ed.), The technology of text: Principles for structuring, designing and displaying text, 53-90. New Jersey: Educational Technology Publication.

Van Fatten, J., Chao, C., and Reigeluth, C. M. (1986). A review of strategies for sequencing and synthesizing instruction. Review of Educational Research, 56(4), 437-471.

Author: Patricia Youngblood, $\mathrm{PhD}$, is Senior Lecturer in Instructional Design at the University of New England, Northern Rivers. Her address is PO Box 157, Lismore, NSW 2480.

Please cite as: Youngblood, P. (1990). The design of a study aid for synthesizing instruction. Australian Journal of Educational Technology, 6(1), 28-35. http: / / www.ascilite.org.au/ajet/ajet6/youngblood.html 